\title{
ARMAZENAGEM EM ATMOSFERA MODIFICADA PASSIVA DE CARAMBOLA AZEDA (Averrhoa carambola L.) CV. 'GOLDEN STAR'1
}

\author{
LEANDRO CAMARGO NEVES ${ }^{2}$, RENAR JOÃO BENDER ${ }^{3}$, CESAR VALMOR ROMBALDI ${ }^{4}$, ROGÉRIO LOPES VIEITES $^{5}$
}

RESUMO - Este trabalho avaliou o efeito das embalagens de polietileno de baixa densidade (PEBD), em diferentes espessuras, no prolongamento da vida útil pós-colheita de carambolas cv. 'Golden Star'. Os frutos foram colhidos físiologicamente maturos, sendo selecionados pela ausência de defeitos e acondicionados nas embalagens de PEBD, constituindo os seguintes tratamentos: T1 - controle (sem embalagem); T2 - PEBD de $6 \mu$ m; T3 - PEBD de $10 \mu \mathrm{m}$; T4 - PEBD de $15 \mu \mathrm{m}$. Os frutos foram armazenados a $12+/-0,5^{\circ} \mathrm{C} \mathrm{e} 95+/-5 \%$ de UR, por 45 dias, e mais 5 dias a $22+/-3^{\circ} \mathrm{C} \mathrm{e} 72+/$ $-5 \%$ de UR. Vinte e quatro horas após a colheita e a cada nove dias, amostras eram retiradas do armazenamento refrigerado (AR), mantidas por 12 horas em condições ambiente $\left(22+/-3^{\circ} \mathrm{C} \mathrm{e} 72+/-5 \%\right.$ UR) e analisadas quanto à firmeza de polpa (FP), à perda de massa fresca, à coloração da epiderme, aos sólidos solúveis totais (SST), à acidez total titulável (ATT) e à ocorrência de distúrbios fisiológicos. Realizou-se também uma análise sensorial ao final do experimento. A maior firmeza de polpa e acidez total titulável, o melhor padrão de coloração, o menor conteúdo de sólidos solúveis totais, a ausência de manchas e podridões, e a melhor aceitabilidade pelos julgadores foram obtidos com os frutos acondicionados em embalagens de $10 \mu \mathrm{m}$.

Termos para indexação: Embalagem de polietileno, pós-colheita PEBD, qualidade.

\section{STORAGE IN PASSIVE MODIFIEDATMOSPHERE OF ‘GOLDENSTAR'STARFRUIT (Averrhoa carambola L.)}

ABSTRACT - This work was carried out to evaluate the effects of low density polyethylene bags (LDPB) with different thickness on Golden Star starfruit shelf life. The fruits were harvested at mature-green ripening stage, selected from lack of defects and placed in LDPB bags, constituting the following treatments: T1 - control (no bags); T2 - $6 \mu$ m thickness LDPB; T3 - $10 \mu \mathrm{m}$ thickness LDPB; T4 - $15 \mu \mathrm{m}$ thickness LDPB. Fruits were stored for 45 days in refrigerated air at $12+/-0,5^{\circ} \mathrm{C}$ and $95+/-3 \% \mathrm{RH}$ and then left at $22+/-3^{\circ} \mathrm{C}$ and $72+/-5 \% \mathrm{RH}$ for 5 days. Twenty-four hours after harvest and every nine days, samples were removed from cold storage, kept for 12 hours in ambient air $\left(22+/-3^{\circ} \mathrm{C}\right.$ and $\left.72+/-5 \% \mathrm{RH}\right)$ and then analyzed for flesh firmness, weight loss, epidermal color, total soluble solids, total titratable acidity, and occurrence of physiological disorders. Fruits were also evaluated by a trained taste panel. Highest values of flesh firmness and titratable acidity, the best color standard, the lowest soluble content as well as decay incidence and the best acceptance scores by the taste panelists were achieved in fruits stored in $10 \mu \mathrm{m}$ thickness LDPB.

Index Terms: polyethylene bags, postharvest, LDPB, quality

\section{INTRODUÇÃO}

No Brasil, a carambola, fruto pertencente à família Oxalidaceae, está distribuída de norte a sul, embora somente na última década a cultura tenha tomado expressão comercial (Araújo, 2000). São Paulo, por sua vez, com uma comercialização de mais de 2.000 t/ano, constitui-se no Estado de maior importância econômica para o fruto. Alguns países asiáticos, como Taiwan e Malásia, e também países sul-americanos, como o Brasil e a Colômbia, estão entre os principais exportadores a mercados potenciais como Europa e EUA (Donadio et al., 2001).

A cultivar 'Golden Star', selecionada na Flórida, apresenta fruto ovóide a elipsóide, 100 a $200 \mathrm{~g}$ de massa, coloração inicialmente verde, passando a amarelo-dourada brilhante quando madura. A polpa é sucosa e ácida, e tem resistência elevada a danos mecânicos e danos de frio (Donadio et al., 2001).

A armazenagem em atmosfera modificada (AM) é uma tecnologia versátil que é aplicada para uma grande quantidade de frutos e hortaliças (Kader, 1992). Segundo Neves et al. (2002) e Mosca et al. (1999), o uso de embalagens de polietileno de baixa densidade (PEBD), associado ao AR, preserva a integridade dos frutos, possibilitando melhor manutenção dos atributos sensoriais.

A utilização da AM, assim como de qualquer outro tratamento pós-colheita, destina-se principalmente a frutos com alto valor comercial (Mosca et al., 1999) que propiciem retorno econômico ao valor investido no tratamento realizado. A AM pode ser uma perspectiva de ampliação de mercado, principalmente o mercado externo. Outro fator positivo da AM é permitir o manuseio direto deste fruto sem resultar em problemas na sua qualidade final (Sarantóupolos \& Soler, 1989).

A modificação da atmosfera, através do uso de filmes plásticos, pode retardar o processo de maturação dos frutos através da alteração da concentração inicial dos gases presentes na embalagem. A concentração de gases resultante nas embalagens depende de alguns fatores, como: taxa de permeabilidade a gases da embalagem, hermeticidade da soldagem, relação área e volume da embalagem, e presença de absorvedores (Sarantóupolos \& Soler, 1989).

Segundo Kader et al. (1989), a seleção de um filme plástico, que resultará em uma $\mathrm{AM}$ favorável, deve ser baseada na taxa respiratória e nas concentrações ótimas de $\mathrm{O}_{2}$ e $\mathrm{CO}_{2}$ para o fruto. Para a maioria dos frutos, exceto aqueles que toleram altos níveis de $\mathrm{CO}_{2}$, um filme adequado deve ser mais permeável ao $\mathrm{CO}_{2}$ que ao $\mathrm{O}_{2}$. Segundo Kader (1992), é necessário preservar uma concentração mínima de $\mathrm{O}_{2}$ dentro das embalagens para que a respiração aeróbia continue ocorrendo normalmente; entretanto, reduções bruscas na concentração de $\mathrm{O}_{2}$ podem levar a uma condição de anaerobiose.

Quando uma embalagem de filme plástico é corretamente projetada, a composição gasosa no interior interfere na atividade metabólica do produto embalado. Nesta condição, há redução da velocidade do metabolismo, obtendo-se, por conseguinte, um retardo na maturação (Mosca et al., 1999).

A partir destas considerações, foi objetivo no presente trabalho estudar o efeito da AM passiva, através da embalagem de polietileno de baixa densidade (PEBD), na pós-colheita da carambola azeda, cv. 'Golden Star', quanto à manutenção da qualidade sensorial e ao prolongamento da vida útil dos frutos, durante o AR.

\section{MATERIALEMÉTODOS}

O experimento foi conduzido no laboratório de Frutas e Hortaliças do Departamento de Gestão e Tecnologia Agroindustrial, da UNESP - Câmpus de Botucatu. Os frutos foram colhidos fisiologicamente maturos, no sítio Shimazaki, localizado no município de Aguaí-SP. As carambolas apresentavam-se com coloração da epiderme verde, firmeza

\footnotetext{
${ }^{1}$ (Trabalho 116/2003). Recebido: 04/09/2003. Aceito para publicação: 16/01/2004.

${ }^{2}$ UFRGS-Doutorando em Fitotecnia, C.P.776, CEP 91501-970, Porto Alegre-RS. rapelbtu@ hotmail.com.

${ }^{3}$ UFRGS-Prof. Dr. Depto de Horticultura, C.P.776, CEP 91501-970, Porto Alegre-RS. rjbe@ ufrgs. br.

${ }^{4}$ UFPel-Prof. Dr. Depto de Ciência e Tecnologia Agroindustrial, C.P. 354, CEP 96010900, Pelotas-RS. cvrf@ufpel.tche.br.

${ }^{5}$ UNESP/FCA Prof. Dr. Depto de Gestão e Tecnologia Agroindustrial, Cx. Postal 247, CEP 18603-970 Botucatu-SP. vieites@ fca.unesp.br.
} 
TABELA 1 - Firmeza de polpa (Lb.pol ${ }^{-1}$ ), perda de massa fresca (\%), coloração (escala subjetiva) e ocorrência de distúrbios fisiológicos (\%), em carambola cv. 'Golden Star', armazenadas sob refrigeração a $12+/-0,5^{\circ} \mathrm{C}$ e $95+/-3 \%$ de UR, durante 45 dias mais 5 dias de condições de comercialização simulada a $22+/-3^{\circ} \mathrm{C}$ e $72+/-5 \%$ de UR, Botucatu-SP.

\section{Dias de Armazenamento}

\begin{tabular}{|c|c|c|c|c|c|c|c|c|}
\hline & trat $/ 0$ & 1 & 9 & 18 & 27 & 36 & 45 & $45+5$ \\
\hline \multirow{4}{*}{$\begin{array}{c}\text { Coloração } \\
\text { (escala subjetiva) }\end{array}$} & s/ PEBD & $5 a$ & $3,33 b$ & $2,33 c$ & $1 \mathrm{c}$ & $1 \mathrm{c}$ & $1 \mathrm{c}$ & $1 \mathrm{c}$ \\
\hline & $6 \mu \mathrm{m}$ & $5 a$ & $5 a$ & $4,33 b$ & $4 b$ & $3,33 b$ & $2,66 b$ & $1 \mathrm{c}$ \\
\hline & $10 \mu \mathrm{m}$ & $5 a$ & $5 a$ & $4,67 b$ & $4 b$ & $4 a b$ & $3,67 \mathrm{ab}$ & $2,66 b$ \\
\hline & $15 \mu \mathrm{m}$ & $5 a$ & $5 a$ & $5 a$ & $5 a$ & $5 a$ & $5 a$ & $5 a$ \\
\hline \multirow{5}{*}{$\begin{array}{c}\text { Perda de Massa } \\
\text { Fresca } \\
(\%)\end{array}$} & C.V. (\%) & 0 & 5,099 & 3,072 & 6,921 & 6,002 & 5,439 & 7,887 \\
\hline & s/ PEBD & $0,033 a$ & $20,73 a$ & $41,53 a$ & $61,07 a$ & $85,27 \mathrm{a}$ & $100 \mathrm{a}$ & $100 \mathrm{a}$ \\
\hline & $6 \mu \mathrm{m}$ & $0 \mathrm{a}$ & $0,92 b$ & $1,15 b$ & $1,46 b$ & $2,27 b$ & $3,5 b$ & $5 b$ \\
\hline & $10 \mu \mathrm{m}$ & $0 \mathrm{a}$ & $0 \mathrm{~b}$ & $0 \mathrm{~b}$ & $0 \mathrm{~b}$ & $0 \mathrm{~b}$ & $0 \mathrm{~b}$ & $0 \mathrm{~b}$ \\
\hline & $15 \mu \mathrm{m}$ & $0 \mathrm{a}$ & $0 \mathrm{~b}$ & $0 \mathrm{~b}$ & $0 \mathrm{~b}$ & $0 \mathrm{~b}$ & $0 \mathrm{~b}$ & $0 \mathrm{~b}$ \\
\hline \multirow{5}{*}{$\begin{array}{l}\text { Firmeza de Polpa } \\
\qquad\left(\text { Lb.pol }^{-1}\right)\end{array}$} & C.V. $(\%)$ & 0 & 1,245 & 2,008 & 1,324 & 2,102 & 1,082 & 1,144 \\
\hline & s/ PEBD & $327,67 a$ & $251 d$ & $172,33 d$ & $101 \mathrm{~d}$ & $33 \mathrm{c}$ & $0 \mathrm{c}$ & $0 \mathrm{c}$ \\
\hline & $6 \mu \mathrm{m}$ & $327,67 \mathrm{a}$ & $285,67 \mathrm{c}$ & $242 \mathrm{c}$ & $196 b$ & $152,33 b$ & $105 b$ & $31,67 b$ \\
\hline & $10 \mu \mathrm{m}$ & $327,67 a$ & $302,33 b$ & $271 b$ & $241 \mathrm{a}$ & $211,33 a$ & $188,33 \mathrm{a}$ & $135,67 a$ \\
\hline & $15 \mu \mathrm{m}$ & $327,67 \mathrm{a}$ & $315,67 \mathrm{a}$ & $304,33 \mathrm{a}$ & $119,67 \mathrm{c}$ & $58,67 \mathrm{c}$ & $0 \mathrm{c}$ & $0 \mathrm{c}$ \\
\hline \multirow{6}{*}{$\begin{array}{l}\text { Distúrbios } \\
\text { Fisiológicos } \\
(\%)\end{array}$} & C.V. (\%) & 0 & 1,020 & 1,117 & 0,899 & 0,870 & 1,455 & 2,190 \\
\hline & s/ PEBD & $0 \mathrm{a}$ & $20 \mathrm{a}$ & $30 a$ & $50 \mathrm{~b}$ & $100 \mathrm{a}$ & $100 \mathrm{a}$ & $100 \mathrm{a}$ \\
\hline & $6 \mu \mathrm{m}$ & $0 \mathrm{a}$ & $0 \mathrm{~b}$ & $0 \mathrm{~b}$ & $5 c$ & $5 b$ & $10 \mathrm{~b}$ & $15 b$ \\
\hline & $10 \mu \mathrm{m}$ & $0 \mathrm{a}$ & $0 \mathrm{~b}$ & $0 \mathrm{~b}$ & $0 \mathrm{c}$ & $0 \mathrm{~b}$ & $0 \mathrm{c}$ & $0 \mathrm{c}$ \\
\hline & $15 \mu \mathrm{m}$ & $0 \mathrm{a}$ & $20 \mathrm{a}$ & $30 \mathrm{a}$ & $60 \mathrm{a}$ & $100 \mathrm{a}$ & $100 \mathrm{a}$ & $100 \mathrm{a}$ \\
\hline & C.V. $(\%)$ & 0 & 8,754 & 8,225 & 4,256 & 5,236 & 8,449 & 9,900 \\
\hline
\end{tabular}

Médias seguidas da mesma letra, na coluna, não diferem entre si, significativamente, ao nível de $5 \%$ de probabilidade, pelo teste de Tukey.

de polpa média de 328 g.f - $^{-1}$, sólidos solúveis totais em média de $6,3^{\circ}$ Brix e acidez total titulável em média de 14,7 Cmol.L-1. Após a seleção, limpeza e padronização, os frutos foram colocados por 12 horas em câmara frigorífica a $5{ }^{\circ} \mathrm{C}$ e $95+/-3 \%$ de UR, visando ao rápido resfriamento. As carambolas foram acondicionadas em embalagens de PEBD $\left(\mathrm{d}=0,925 \mathrm{~g} . \mathrm{cm}^{-}\right.$ ${ }^{3}$ ), de diferentes espessuras, e colocados em câmara frigorífica com $12+1$ $-0,5^{\circ} \mathrm{C}$ e $95+/-3 \%$ de UR. Os tratamentos foram os seguintes: T1 controle (sem embalagem); T2 - PEBD de $6 \mu \mathrm{m}$ (Taxa permeabilidade ao $\mathrm{O}_{2} / \mathrm{CO}_{2}=17.108 / 73.663 \mathrm{~cm}^{-3} \cdot \mathrm{m}^{-2} \cdot \mathrm{dia}^{-1}$ ); T3 - PEBD de $10 \mu \mathrm{m}$ (Taxa permeabilidade ao $\left.\mathrm{O}_{2} / \mathrm{CO}_{2}=14.231 / 63.850 \mathrm{~cm}^{-3} \cdot \mathrm{m}^{-2} \cdot \mathrm{dia}^{-1}\right)$; $\mathrm{T} 4-\mathrm{PEBD}$ de $15 \mu \mathrm{m}$ (Taxa permeabilidade ao $\mathrm{O}_{2} / \mathrm{CO}_{2}=10.152 / 46.418 \mathrm{~cm}^{-3} \cdot \mathrm{m}^{-2} \cdot \mathrm{dia}^{-1}$ ). Cada embalagem tinha dimensões $0,25 \times 0,20 \mathrm{~m}$, contendo cinco frutos por embalagem. As carambolas foram armazenadas por 45 dias e mais 5 dias a $22+/-3^{\circ} \mathrm{C}$ e $72+/-5 \%$ de UR. As análises foram realizadas 24 horas após a colheita e a cada nove dias, sempre 12 horas após a retirada de cada amostra da câmara e abertura das embalagens, segundo:

- A coloração da casca: baseada em uma escala subjetiva de valores, segundo critérios dos autores, levando em consideração o desenvolvimento da coloração nos frutos, variando de 1 a 5 , onde $1=$ amarela; $2=70 \%$ da epiderme amarela; $3=50 \%$ verde, $50 \%$ amarelada; $4=$ $70 \%$ da epiderme verde, e $5=$ verde;

- A perda de massa fresca: avaliada através da pesagem dos frutos (20 repetições embaladas individualmente, com dimensões de 0,10 x $0,08 \mathrm{~m}$ ), considerando o peso inicial de cada amostra, com resultados expressos em porcentagem;

- A firmeza de polpa (FP): avaliada através do texturômetro modelo "STEVENS - LFRA texture analyser", com a distância de penetração de $20 \mathrm{~mm}$ e velocidade de $2,0 \mathrm{~mm} / \mathrm{seg}$., utilizando o ponteiro TA 9/1000. A leitura foi feita em lados opostos da seção equatorial dos frutos, considerando o valor médio das duas leituras para determinar-se a firmeza em $\mathrm{g} . \mathrm{f}^{-1}$.;

- Os sólidos solúveis totais (SST): avaliados através da leitura refratométrica direta, com o refratômetro tipo Abbe, marca ATAGO - N1. Resultados expressos em ${ }^{\circ}$ Brix;

- A acidez total titulável (ATT): avaliada através de titulometria de neutralização $(\mathrm{NaOH}=0,01 \mathrm{~N})$, com ponto de viragem no $\mathrm{pH}=8,2$, e resultados expressos em Cmol.L $\mathrm{L}^{-1}$;

- A ocorrência de degenerescência da polpa e mancha nos frutos: avaliadas através da porcentagem de frutos (20 repetições embaladas individualmente, com dimensões de $0,10 \times 0,08 \mathrm{~m}$ ), por tratamento, com a presença dos sintomas em mais de $25 \%$ da polpa/ epiderme.

Realizou-se, ao final do experimento, um teste de preferência, através do qual se faz uma avaliação global dos frutos, levando em consideração os atributos físico-químicos e sensoriais, englobados em um só fator de escolha, contando com quinze julgadores treinados, através de escala hedônica de 5 pontos (Moraes, 1988) - gostei muitíssimo (nota 5); gostei muito (nota 4); gostei (nota 3); desgostei muito (nota 2) e desgostei muitíssimo (nota 1 ).

O delineamento experimental empregado foi o inteiramente casualizado, seguindo um esquema fatorial $4 \times 7$ (4 tipos de embalagem e 7 períodos de armazenamento), com 4 tratamentos e 20 repetições para as análises não destrutivas ( perda de massa fresca e distúrbios fisiológicos) e 5 repetições para as análises destrutivas (coloração, FP, SST, ATT). Os dados foram submetidos à análise de variância e à comparação de médias pelo teste de Tukey $(\mathrm{P}=0,05)$. Todas as análises das variáveis estudas foram executadas pelo programa StatGraphics.

\section{RESULTADOSE DISCUSSÃO}

Detectou-se um decréscimo da FP ao longo do período experimental, constatando diferença significativa entre os frutos com e sem embalagem, bem como entre as diferentes espessuras de PEBD utilizadas (Tabela 1). Os frutos-controle e os frutos acondicionados nas embalagens de $15 \mu \mathrm{m}$ apresentaram as maiores perdas. Estes frutos, aos 36 dias de AR, já apresentaram FP bem abaixo dos demais tratamentos, sendo que, a partir dos 45 dias de AR, não tinham FP mensurável pelo método de análise utilizado. A simples manutenção da AR por um tempo prolongado, sem a utilização da embalagem de PEBD, não foi suficiente para controlar a drástica diminuição da FP dos frutos-controle. Já nos frutos acondicionados nas embalagens de $15 \mu \mathrm{m}$, possivelmente, a utilização de um filme plástico excessivamente espesso tenha favorecido uma condição de anaerobiose (Mosca et al., 1999; Neves et al., 2002), ocasionando um descontrole no metabolismo normal dos frutos ao longo do $\mathrm{AR}$, proporcionando uma rápida perda de FP. A melhor manutenção dos valores de FP foi observada nos frutos embalados em filmes de PEBD de $10 \mu \mathrm{m}$. Tal fato, segundo Kader et al. (1989) e Kader (1992), dá-se pela correta associação entre o tipo 
de fruto e espessura do filme de PEBD utilizado. A elevação dos níveis de $\mathrm{CO}_{2}$ e a diminuição dos níveis de $\mathrm{O}_{2}$, através do uso de embalagens plásticas, até concentrações não prejudiciais, preservam a integridade dos tecidos celulares, possibilitando, entre outros fatores, a redução da taxa e da velocidade das perdas de FP dos frutos.

Durante o período de avaliação, constatou-se a interferência da embalagem de PEBD nas porcentagens das perdas de massa fresca dos frutos (Tabela 1). As maiores perdas, verificadas nos frutos-controle, chegaram a aproximadamente $86 \%$ aos 36 dias de AR, descaracterizando totalmente a qualidade destes frutos. A partir dos 45 dias de AR, pela completa falta de FP e surgimento de podridões na polpa e epiderme, determinou-se a perda máxima (100\%) de massa fresca nos frutos-controle. Comportamento semelhante foi observado em caquis cv. Giombo, (Antoniolli et al., 2001); em mangas 'Tommy Atkins' (Souza et al., 2002); em atemoyas cv. PR3 (Yamashita et al., 2002), onde frutos armazenados em AR, sem a utilização de embalagens de PEBD, apresentaram maiores perdas de massa fresca em comparação aos frutos embalados. Os frutos acondicionados nas embalagens de 6; 10 e $15 \mu \mathrm{m}$, por sua vez, não apresentaram diferença estatística entre si. No entanto, a partir dos 45 dias de AR, a exemplo dos frutos-controle, os frutos acondicionados nas embalagens de $15 \mu \mathrm{m}$, provavelmente devido ao elevado estado fermentativo, já não apresentavam um padrão de qualidade adequado. Já, os frutos das embalagens de $10 \mu \mathrm{m}$ apresentaram excelente controle das perdas de massa fresca, além da manutenção dos atributos sensoriais ao longo de todo o período experimental. A redução nas perdas de massa fresca observada nos frutos em AM, possivelmente, seja decorrente do aumento da umidade relativa do ar no interior das embalagens, saturando a atmosfera ao redor dos frutos, levando à diminuição do défice de pressão de vapor d'água e, conseqüentemente, reduzindo a transpiração dos frutos.

A embalagem de PEBD e, principalmente, a permeabilidade do filme plástico utilizado influíram significativamente no desenvolvimento da coloração das carambolas cv. 'Golden Star' (Tabela 1). Em uma préanálise, aos 27 dias de AR, todos os frutos embalados, à exceção dos frutos das embalagens de $15 \mu \mathrm{m}$, apresentavam uma evolução da coloração mais lenta do que os frutos-controle. Neste ponto, os frutoscontrole já apresentavam uma coloração amarelada em toda a superfície, demonstrando, prematuramente, um avançado estádio de amadurecimento. Este comportamento, segundo alguns autores (Souza et al., 2002; Neves et al., 2002; Yamashita et al., 2001; Mosca et al., 1999), pode ser explicado pelo fato de que a embalagem, quando corretamente projetada, diminui a velocidade do metabolismo do fruto, atrasando o amadurecimento. Nos frutos acondicionados nas embalagens de $15 \mu \mathrm{m}$, possivelmente devido à maior espessura do filme de PEBD utilizado, tenha-se elevado a concentração de $\mathrm{CO}_{2}$ e diminuído a concentração de $\mathrm{O}_{2}$ presente na atmosfera gasosa das embalagens, não ocorrendo assim a degradação da clorofila e manifestação dos carotenóides, que, segundo Donadio et al. (2001), são os pigmentos responsáveis pela coloração amarelo-dourada da cv. 'Golden Star'. Estes dados são concordantes com Kader (1992), onde é mencionado o efeito da AM no controle da degradação da clorofila nos frutos. No entanto, os frutos acondicionados nas embalagens de $10 \mu \mathrm{m}$ apresentavam, após a simulação de comercialização, uma coloração predominantemente amarelada e, aparentemente, em estádio menos avançado de amadurecimento que os demais tratamentos. Assim, pressupõe-se um aumento no período seguro de comercialização, com adequada manutenção da qualidade destes frutos.

Os distúrbios fisiológicos (Tabela 1) foram caracterizados neste experimento pelo surgimento de manchas escuras na superfície e polpa dos frutos (Donadio et al., 2001), bem como podridões decorrentes do acelerado processo de amadurecimento, estando condicionado a fatores distintos nos frutos-controle e nos frutos das embalagens de $15 \mu \mathrm{m}$. Nos frutos-controle, provavelmente, as perdas excessivas de FP e de massa fresca, ocasionadas pelo intenso processo de amadurecimento, tenham contribuído, decisivamente, para o comprometimento da sanidade destes frutos no período entre os 18 e os 27 dias de AR. Quanto aos frutos acondicionados nas embalagens de $15 \mu \mathrm{m}$, a baixa permeabilidade do filme de PEBD utilizado desencadeou o avanço de um processo fermentativo, comprometendo a qualidade sensorial destes frutos aos 27 dias de AR. Os frutos embalados em filme de PEBD de $10 \mu \mathrm{m}$ foram os que obtiveram melhores resultados, apresentando-se, ao final do experimento, sem nenhuma manifestação de danos físicos e/ou podridões, possibilitando assim maior flexibilidade quanto ao seu tempo de conservação pós-colheita. O mesmo foi citado por Sarantóupolos \& Soler (1989), nos quais são descritos os efeitos positivos da embalagem, quanto à criação de uma barreira de proteção que separa os frutos do contato direto com o meio, preservando assim a integridade física dos mesmos e prolongando a vida útil pós-colheita.

Nas análises de SST e ATT, os frutos-controle e os frutos acondicionados nas embalagens de $15 \mu \mathrm{m}$ não foram avaliados a partir dos 36 dias, devido à completa degradação e, conseqüientemente, falta de condições para análise.

O teor de SST sofreu elevação progressiva, em todos os frutos, durante o período de avaliação (Figura 1). A embalagem de PEBD proporcionou contenção na velocidade do desenvolvimento dos teores de SST. Este comportamento contraria alguns autores (Donadio et al., 2001), onde carambolas da cv. 'Goden Star' são caracterizadas como frutos não climatéricos. Embora, segundo os mesmos autores, ainda existam contradições a respeito do padrão respiratório destes frutos. Entretanto, neste experimento, a razão para o incremento nos teores de SST, supostamente, deve-se à desidratação parcial destes frutos durante o período de amadurecimento, concentrando, portanto, o conteúdo celular. Os maiores incrementos foram detectados nos frutos-controle, já aos 36 dias de AR, comprovando sua alta atividade metabólica em relação aos demais tratamentos. Os frutos acondicionados nas embalagens de $10 \mu \mathrm{m}$ apresentaram-se com os menores teores de SST ao final do experimento, demonstrando diminuição na velocidade do metabolismo, aparentando estádio menos avançado de amadurecimento. Estes dados são concordantes com Souza et al. (2002) e Yamashita et al. (2002), onde a diminuição na atividade metabólica dos frutos embalados se deve à modificação atmosférica no interior das embalagens,

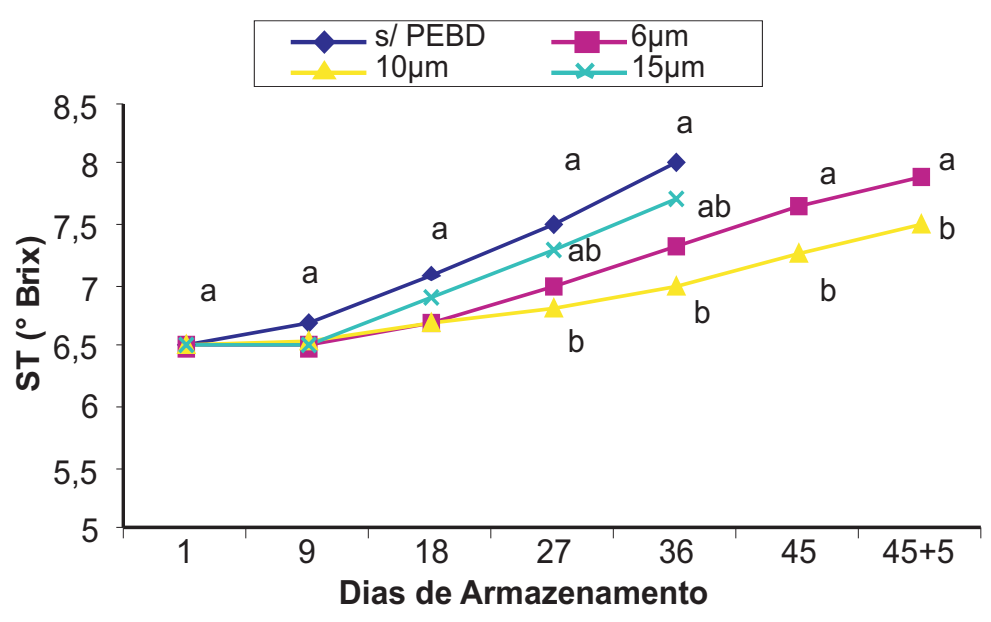

Médias seguidas da mesma letra não diferem entre si, significativamente, ao nível de $5 \%$ de probabilidade, pelo teste de Tukey.

FIGURA 1 - Sólidos solúveis totais ( ${ }^{\circ}$ Brix), em carambola cv. 'Golden Star', armazenadas sob refrigeração a $12+/-0,5^{\circ} \mathrm{C}$ e $95+/-$ $3 \%$ de UR, durante 45 dias mais 5 dias de condições de comercialização simulada a $22+/-3^{\circ} \mathrm{C}$ e $72+/-5 \%$ de UR, Botucatu-SP.

proporcionando contenção nos teores de SST.

A ATT das carambolas cv. 'Golden Star', nos diferentes tratamentos, apresentou tendência de diminuição no decorrer do AR e simulação de comercialização (Figura 2). Segundo Yamashita et al. (2002), a maior parte dos frutos apresenta decréscimos nos níveis de ATT ao longo do amadurecimento. No entanto, neste trabalho, percebeu-se que 
este declínio ocorreu de maneira menos acentuada nos frutos em AM. Este comportamento indica que houve retenção no metabolismo de transformação dos ácidos orgânicos pelo uso das embalagens. Os frutos acondicionados nas embalagens de PEBD de $10 \mu \mathrm{m}$ foram os que apresentaram os maiores níveis de ATT ao final do experimento, pressupondo-se um estádio menos avançado de amadurecimento. BenArie \& Zutkhi (1992) descrevem que, em caquis da cv. Fuyu, embalados em sacos de PEBD, é possível constatar que a contenção da diminuição dos teores de ATT está diretamente relacionada com a melhor conservabilidade. No entanto, Antoniolli et al. (2002), trabalhando com caquis cv. Giombo, Yamashita et al. (2001), trabalhando com mangas cv. 'Tommy Atkins', e Moura et al. (1997), trabalhando com caquis cv. Taubaté, não observaram influência da AM na manutenção dos níveis de AT dos frutos. Já Yamashita et al. (2002), trabalhando com atemoyas cv. PR3, mantiveram constantes os níveis de AT dos frutos durante o AR e em condições ambiente através do uso de filmes plástico de PEBD. Deste modo, condiciona-se o efeito da AM, em relação à ATT, ao tipo de filme

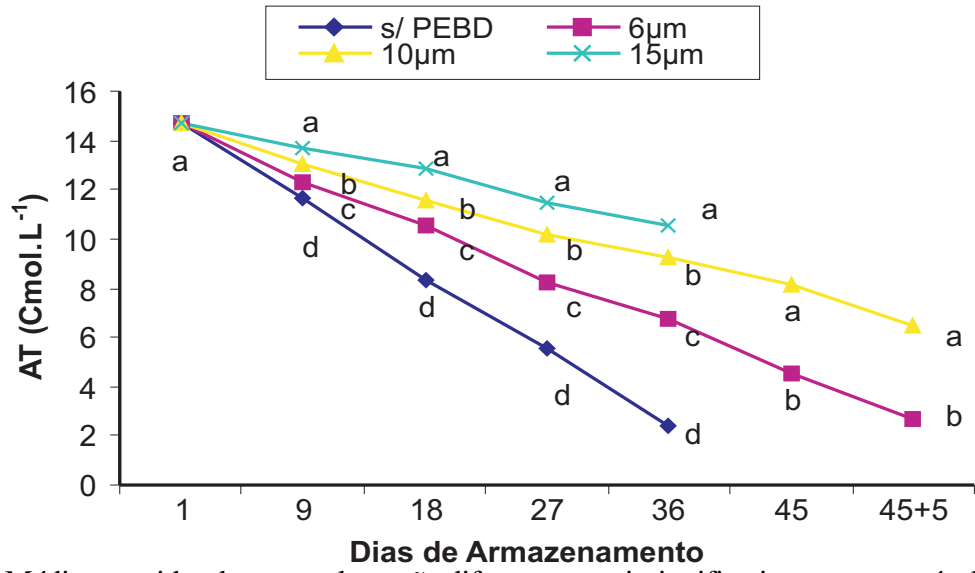

Médias seguidas da mesma letra não diferem entre si, significativamente, ao nível de $5 \%$ de probabilidade, pelo teste de Tukey.

FIGURA 2-Acidez total titulável, em carambola cv. 'Golden Star' (Cmol. $\left.\mathrm{L}^{-1}\right)$, armazenadas sob refrigeração a $12+/-0,5^{\circ} \mathrm{Ce}$ $95+/-3 \%$ de UR, durante 45 dias mais 5 dias de condições de comercialização simulada a $22+/-3^{\circ} \mathrm{C}$ e $72+/-5 \%$ de UR, Botucatu-SP.

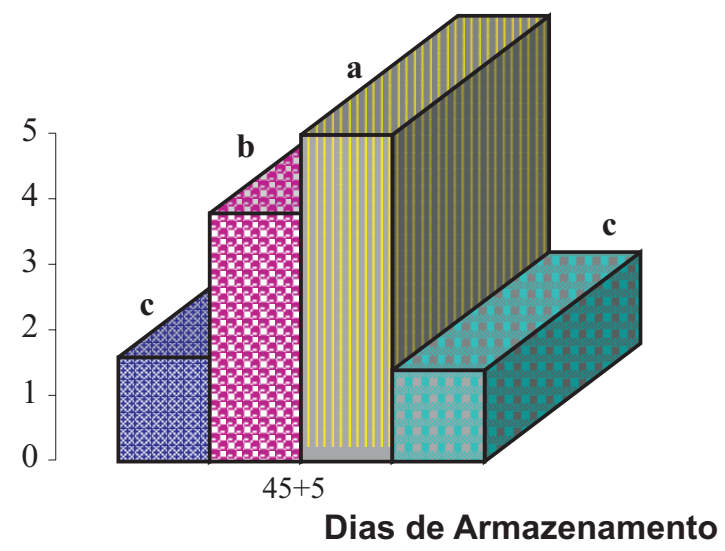

圆s/ PEBD
固6 $\mu \mathrm{m}$
$\square 10 \mu \mathrm{m}$
$\square 15 \mu \mathrm{m}$

Médias seguidas da mesma letra não diferem entre si, significativamente, ao nível de $5 \%$ de probabilidade, pelo teste de Tukey.

FIGURA 3 - Análise sensorial, em carambola cv. 'Golden Star', através de teste de preferência, armazenadas sob refrigeração a 12 +/- $0,5^{\circ} \mathrm{C}$ e $95+/-3 \%$ de UR, durante 45 dias mais 5 dias de condições de comercialização simulada a $22+/-3^{\circ} \mathrm{C}$ e $72+/$ - $5 \%$ de UR, Botucatu-SP.

utilizado, sua permeabilidade, bem como ao tipo de fruto embalado e suas características individuais.

Ao final do experimento, os frutos acondicionados nas embalagens de $10 \mu \mathrm{m}$ apresentaram os melhores índices de preferência frente aos julgadores (Figura 3). Isto comprova que os melhores resultados obtidos nas análises físico-químicas convergem para o mesmo tratamento escolhido pelos julgadores na análise sensorial. Já os frutos acondicionados nas embalagens de $15 \mu \mathrm{m}$, pelo avançado estado de fermentação dos frutos, e os frutos-controle, pelo adiantado estádio de amadurecimento, induziram os julgadores à rejeição destes frutos. Deste modo, fica evidenciada a eficácia da embalagem de PEBD, quando corretamente projetada (Mosca et al., 1999), na manutenção da qualidade dos frutos, bem como no prolongamento da vida útil (Kader, 1992).

\section{CONCLUSÕES}

A utilização da embalagem de polietileno de baixa densidade, com $10 \mu \mathrm{m}$ de espessura, em carambolas cv. 'Golden Star', permite um período seguro de 45 dias de AR, com adequada manutenção dos atributos físico-químicos e sensoriais.

\section{REFERÊNCIASBIBLIOGRÁFICAS}

ANTONIOLLI, L.R.; CASTRO, P.R.de C.; KLUGE, R.A.; FILHO, J.A.S. Influência da embalagem de polietileno na remoção da adstringência e na qualidade de caquis (Diospyrus kaki L.), cv. Giombo, armazenados sob refrigeração. Revista Brasileira de Fruticultura, Jaboticabal, v.23, n.2, p.293-297, 2001.

ARAÚJO, P.S.R. de. Seleção da caramboleira (Averrhoa carambola L.) relacionada às características biométricas e fisico-química dos frutos. 2000, 5f. Tese (Doutorado) - Escola Superior de Agricultura "Luiz de Queiroz", Universidade de São Paulo, Piracicaba. 2000.

BEN-ARIE; ZUTKHI, Y. Extending the storage life of "Fuyu" persimmon by modified atmosphere packaging. HortScience, Alexandria v.27, n.7, p.811 -813, 1992.

DONADIO, L.C.; SILVA, J.A.A.; ARAÚJO, P.R.S.; PRADO, R. de M. Caramboleira (Averrhoa carambola L.) Jaboticabal: Sociedade Brasileira de Fruticultura, 2001. 81p.

KADER, A. A.; ZAGORYD, D.; KERBER, E. L. Modified atmosphere packaging of fruits and vegetables. Cri. Ver. Food Sci. Nutra., v.2, n.1, p.1-30, 1989.

KADER, A.A. Postharvest technology of horticultural crops. $5^{\text {th }}$ ed. Berkeley: University of California, 1992.

MORAES, M.A.C. Métodos para avaliação sensorial dos alimentos. 6 . ed. Campinas: Editora Unicamp, 1988.

MOSCA, J. L.; MUGNOL, M. M.; VIEITES, R. L. Atmosfera modificada na pós-colheita de frutas e hortaliças. Botucatu: FEPAF, 1999, 28p.

MOURA, M.A.; LOPES, L.C.; CARDOSO, A.A.; MIRANDA, L.C.G. Efeito da embalagem e do armazenamento no amadurecimento do caqui. Pesquisa Agropecuária Brasileira, Brasília, v.32, n. 6, p.1105$1109,1997$.

NEVES, L.C.; RODRIGUES, A.C.; VIEITES, R.L. Polietileno de baixa densidade (PEBD) na conservação pós-colheita de figos cv. "Roxo de Valinhos". Revista Brasileira de Fruticultura, Jaboticabal, v.24, n.1, p.57-62, 2002.

SARANTÓUPOLOS, I. G. L.; SOLER, R. M. Embalagens com atmosfera modificada/controlada. In: SARANTÓUPOLOS, I. G. L.; SOLER, R. $M$. Novas tecnologias de acondicionamento de alimentos: embalagens flexíveis e semi-rígidas. Campinas: Ital, 1989. Cap. 5, p. 104-140.

SOUZA, J.P. de; PRAÇA, E.F.; ALVES, R.E.; NETO, F.B.; DANTAS, F.F. Influência do armazenamento refrigerado em associação com atmosfera modificada por filmes plásticos na qualidade de mangas 'Tommy Atkins'. Revista Brasileira de Fruticultura, Jaboticabal, v.24, n.3, p.665-668, 2002.

YAMASHITA, F.; MIGLIORANZA, L.H. da S.; MIRANDA, L. de A.; SOUZA, C.M. de A. Effects of packaging and temperature on postharvest of atemoya. Revista Brasileira de Fruticultura, Jaboticabal, v.24, n.3, p.658-660, 2002. 